\title{
The thermodynamic state of the Arctic atmosphere observed by AIRS: comparisons during the record minimum sea ice extents of 2007 and 2012
}

\author{
A. Devasthale ${ }^{1}$, J. Sedlar ${ }^{1}$, T. Koenigk ${ }^{2}$, and E. J. Fetzer ${ }^{3}$ \\ ${ }^{1}$ Atmospheric Remote Sensing Unit, Research and Development Department, Swedish Meteorological and Hydrological \\ Institute (SMHI), Norrköping, Sweden \\ ${ }^{2}$ Rossby Center for Climate Research, Swedish Meteorological and Hydrological Institute (SMHI), Norrköping, Sweden \\ ${ }^{3}$ JPL/CALTECH, NASA, Pasadena, California, USA
}

Correspondence to: A. Devasthale (abhay.devasthale@ smhi.se)

Received: 19 November 2012 - Published in Atmos. Chem. Phys. Discuss.: 4 January 2013

Revised: 1 July 2013 - Accepted: 2 July 2013 - Published: 2 August 2013

\begin{abstract}
The record sea ice minimum (SIM) extents observed during the summers of 2007 and 2012 in the Arctic are stark evidence of accelerated sea ice loss during the last decade. Improving our understanding of the Arctic atmosphere and accurate quantification of its characteristics becomes ever more crucial, not least to improve predictions of such extreme events in the future. In this context, the Atmospheric Infrared Sounder (AIRS) instrument onboard NASA's Aqua satellite provides crucial insights due to its ability to provide 3-D information on atmospheric thermodynamics.

Here, we facilitate comparisons in the evolution of the thermodynamic state of the Arctic atmosphere during these two SIM events using a decade-long AIRS observational record (2003-2012). It is shown that the meteorological conditions during 2012 were not extreme, but three factors of preconditioning from winter through early summer played an important role in accelerating sea ice melt. First, the marginal sea ice zones along the central Eurasian and North Atlantic sectors remained warm throughout winter and early spring in 2012 preventing thicker ice build-up. Second, the circulation pattern favoured efficient sea ice transport out of the Arctic in the Atlantic sector during late spring and early summer in 2012 compared to 2007. Third, additional warming over the Canadian archipelago and southeast Beaufort Sea from May onward further contributed to accelerated sea ice melt. All these factors may have lead the already thin and declining sea ice cover to pass below the previous sea ice extent minimum
\end{abstract}

of 2007. In sharp contrast to 2007, negative surface temperature anomalies and increased cloudiness were observed over the East Siberian and Chukchi seas in the summer of 2012. The results suggest that satellite-based monitoring of atmospheric preconditioning could be a critical source of information in predicting extreme sea ice melting events in the Arctic.

\section{Introduction and perspectives from the summer of 2007}

The record Arctic sea ice minimum (SIM) extent during summer 2007 (Stroeve et al., 2008) was the most palpable manifestation of accelerated climate change and of the so-called Arctic amplification during recent decades. Although the declining trend in sea ice extent had been well known prior to the 2007 SIM, the magnitude and timing of such a decline was not foreseen. The 2007 SIM event challenged our already limited understanding (reflected in large inter-model differences) of the processes influencing sea ice variability and atmosphere-ocean-cryosphere interactions.

A number of studies have shed light on the role of various drivers of the 2007 sea ice melt. Kay et al. (2008) showed that the effect of warm air advection, reduced cloudiness, and increased shortwave surface flux over the Beaufort high region may have contributed to the observed sharp decline in sea ice. Over this region, the lower troposphere warmed by 
2-3 K while more persistent and stronger temperature inversions were observed (Devasthale et al., 2010). However, the role of reduced cloudiness and increased downwelling shortwave radiation was questioned by Schweiger et al. (2008) using an ocean-ice model. L'Heureux et al. (2008) argued for the role of an anomalously strong Pacific-North American (PNA) pattern in influencing the unusual atmospheric circulation during 2007. The preconditioning of winds, thermodynamic and surface parameters prior to the melt season were also argued to be important factors (Sedlar and Devasthale, 2012; Graversen et al., 2011; Vihma et al., 2008; Zhang et al., 2008). Using ice mass balance observations, Perovich et al. (2008) further suggested that the additional solar heating of the upper layers of ocean was a primary cause of Beaufort sea ice bottom melting. The continued decrease in sea ice extent during the recent years could be due to recent largescale changes in atmospheric circulation, trends in cloudiness, increased ocean heat flux into the Arctic, or continuous thinning of the sea ice (Comiso, 2012; Deser and Teng, 2008; Kay and Gettelman, 2009; Kwok et al., 2009; Kwok and Rothrock, 2009; Lindsay et al., 2009; Liu et al., 2009, 2012; Maslanik et al., 2007a, b; Ogi and Wallace, 2007; Overland and Wang, 2010; Skagseth et al., 2008; Woodgate et al., 2010). Apart from the processes mentioned above, it must be noted that increased greenhouse gas forcing is actually the primary driver for the rapid onset of the sea ice decline (Notz and Marotzke, 2012).

Already in August 2012, ice extent in the Arctic was below the previous record minimum of September 2007. Figure 1 shows the mean sea ice concentrations of September 2007 and 2012. The spatial structure and magnitude of sea ice concentration were different during these two years, as we will show later, mainly due to different thermodynamic and dynamic controls. From a scientific point of view, the SIM event in 2007 provided an unsolicited opportunity to gain insights into the different influences concerning sea ice spatiotemporal variability, partly because modern satellite observations contain detailed 3-D information about the state of the atmosphere.

It should be stressed here that, even after removing a linear trend in the September sea ice extent, 2007 and 2012 rank as years with the most anomalous sea ice melt in the satellite era (i.e. from 1979 onwards). Although the trend in sea ice decline is steepest during the past decade (a period for which the most 3-D satellite observations are available), the melting events of 2012 and 2007 still rank at the top during that period. The long-term trend alone cannot fully explain the anomalous sea ice melt during these years and, therefore, the role of atmospheric preconditioning becomes an important premise for eventual acceleration or retardation of sea ice melt in summer. The investigation of the thermodynamic state of the atmosphere during such strong anomalous years is an essential first step towards gaining insights into the role of atmospheric preconditioning. This is a main focus of the present study. Furthermore, this information can

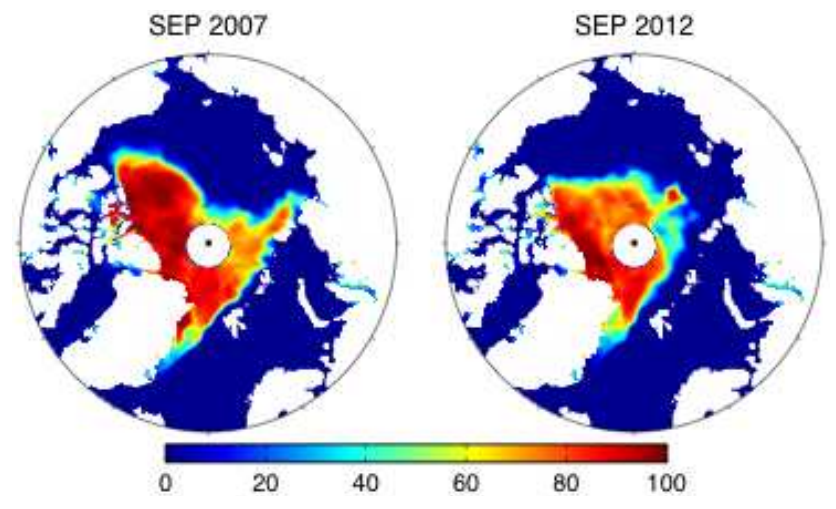

Fig. 1. Monthly mean sea ice concentration (contours [\%]) for September 2007 and 2012. Sea ice concentration data are taken from the Nimbus-7 Scanning Multichannel Microwave Radiometer (SMMR) Defense Meteorological Satellite Program (DMSP), Special Sensor Microwave/Imager (SSM/I), Special Sensor Microwave Imager/Sounder (SSMIS). Passive Microwave data set using Platform F13 and near-real-time Platform F17 (Cavalieri et al., 1996).

be exploited (a) to seek commonalities/differences, which can further be used to evaluate atmospheric response in forecasting models during SIM events, identify weaknesses in them and thereby improve their skill, and (b) to provide useful information to understand processes that drive such extreme events. In this context, in the present study, we examine similarities and differences in the state of the Arctic atmosphere during 2007 and 2012 leading up to the corresponding SIM events. We exploit data obtained from the Atmospheric Infrared Sounder (AIRS) instrument that is flying onboard NASA's Aqua satellite since 2002 and providing 3-D information on atmospheric thermodynamics at unprecedented resolutions and accuracy.

\section{AIRS data}

For the present study, we use data from the Atmospheric Infrared Sounder (AIRS)/Advanced Microwave Sounding Unit (AMSU) instrument suite (Chahine et al., 2006). The AIRS grating spectrometer has a total of 2378 infrared channels, with a spectral coverage between 3.7 and $15.4 \mu \mathrm{m}$. Temperature and water vapour profiles are calculated at approximately $40 \mathrm{~km}$ spatial resolution at nadir view. AIRS scans in both directions to $49.5^{\circ}$ off nadir, providing near-global coverage on a daily basis. Here, the AIRS Daily L3 Version 5 (V5) standard product is used. In this study, we the retrievals of temperature, water vapour, geopotential height and cloud cover from December 2002 through August 2012. Over the years, AIRS data sets have matured considerably, and a wealth of literature on the validation of AIRS retrievals is now available (e.g. Divakarla et al., 2006; Fetzer, 2006; Gettelman et al., 2006; Kahn et al., 2008). The L3 standard product has previously been used for studying 
large-scale climatic features over the high latitudes (Devasthale et al., 2010, 2011, 2012; Sedlar and Devasthale, 2012). The temperature and water vapour profiles from AIRS have reached validation stage 3, meaning "the uncertainties in the product are well-established via independent measurements made in a systematic and statistically robust way that represents global conditions" (http://airs.jpl.nasa.gov/data/ product_accuracies/). The stated accuracies for temperature and Special Sensor Microwave Imager/Sounder (WV) profiles are $1 \mathrm{~K} \mathrm{~km}^{-1}$ and $15 \% 2 \mathrm{~km}^{-1}$, respectively. The Level 3 products used here have been especially screened for "best" or "good" quality Level 2 retrievals, meaning that these products can be used for statistical climate studies such as the present study.

\section{Similarities and differences between 2007 and 2012 SIM events}

\subsection{Winter evolution}

In the winter of 2006-2007, the Arctic Oscillation (AO), the most dominant mode of variability over the Arctic, was in the positive phase during December, January and March and was in the negative phase during February 2007. The phase of the AO mentioned here is based on an AO index provided by The National Oceanic and Atmospheric Administration's (NOAA) Climate Prediction Center. The AO index is calculated by projecting $1000 \mathrm{hPa}$ height anomalies poleward of $20^{\circ} \mathrm{N}$ onto the loading pattern of $\mathrm{AO}$, which in turn is the leading mode of the empirical orthogonal function analysis of monthly mean $1000 \mathrm{hPa}$ height anomalies for a certain climatological period (in this particular case 19792000). In the winter of 2011-2012, positive AO was observed during December and March while negative during January and February. The corresponding geopotential height anomalies at $500 \mathrm{hPa}$ for 2007 and 2012 are shown in Fig. 2. The monthly anomalies of different atmospheric state variables shown here are with respect to climatologies corresponding to those particular months. All monthly anomalies below 1 standard deviation (sigma level) of the 2003-2012 time series are masked, and therefore the anomalies remaining are considered significant relative to the mean monthly conditions of 2003-2012. The marginal sea ice zones along the Kara and Barents seas, in addition to the Laptev Sea and portions of the East Siberian Sea in January, experienced anomalously large geopotential heights resulting in a thicker and relatively warmer atmospheric column in the late winter of 2011-2012. The same regions during 2006-2007 indicate anomalously low $500 \mathrm{hPa}$ geopotential heights (Fig. 2). Additionally, a distinct positive geopotential anomaly over west-central Eurasia and neighbouring seas was persistent during winter 20112012, opposite to the generally negative anomalies in the same regions and season during 2006-2007. Anomalously low geopotential heights were present during much of win-
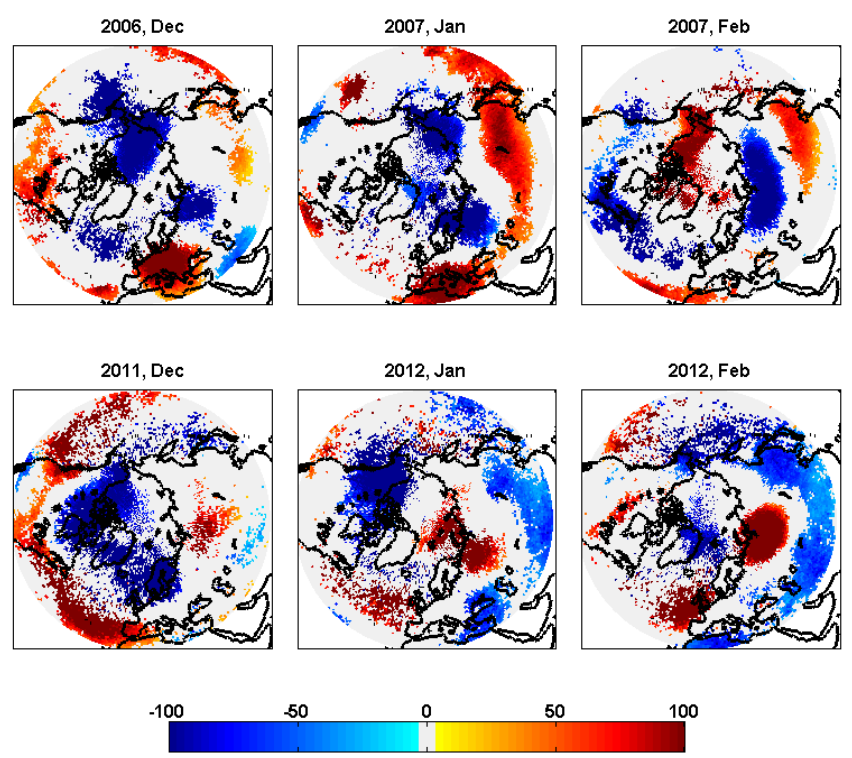

Fig. 2. Geopotential height anomalies [m] for the DJF months of 2006/07 (top row) and 2011/12 (bottom row). The regions with anomalies less than one standard deviation masked out.

ter 2011-2012 over the northern North American continent and Canadian archipelago, whereas similar negative height anomalies occurred during 2006-2007 but were further north over the sea ice (Fig. 2).

The surface skin temperature anomalies shown in Fig. 3 reflect the large-scale circulation differences for winter. While a significant warming ranging from $2-5 \mathrm{~K}$ was observed over the Laptev and Kara seas during 2011-2012, in contrast, the strong warming was only observed during February and from the Pacific sector in the winter of 20062007, in accordance with the different circulation patterns. There were little significant surface temperature anomalies over northern Canada and the Canadian archipelago during December and January 2011-2012 (Fig. 3), consistent with the dominant low geopotential height anomalies over those regions (Fig. 2). An exception was the sea ice region directly adjacent to northern Alaska, where significant surface cooling of nearly $3 \mathrm{~K}$ was observed. Figure 4 shows the vertical profiles of temperature and water vapour mixing ratio anomalies averaged over $65-75^{\circ} \mathrm{N}$ for the two winters. These anomalies indicate that the significant warming signal observed at the surface during 2011-2012 over the Eurasian regions exceeded the 1-sigma level from the surface up to $400 \mathrm{hPa}$, and similarly the cooling over the North American continent was also present through a majority of the atmosphere (Fig. 4). Unlike 2011-2012, the significant surface warming during January 2007 over Eurasia extended vertically but over a shallower atmospheric layer above the surface, while the same region experienced a deep anomalous cooling during the following month of February (Fig. 4). Vertical water vapour mixing ratio anomalies 

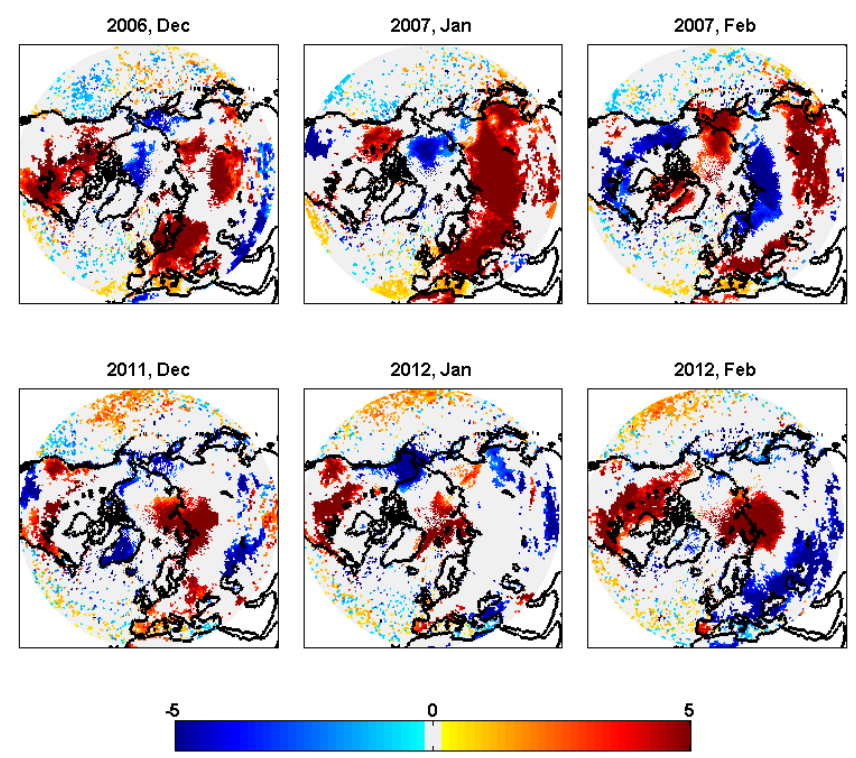

Fig. 3. Surface temperature anomalies $[K]$ for the DJF months. The regions with anomalies less than one standard deviation masked out.

generally show the same anomalous sign as temperature, following thermodynamic principles. This resulted in a warmer and moister Eurasia and neighbouring seas and a cooler, drier atmosphere over North American neighbouring seas during winter 2011-2012.

\subsection{Spring evolution}

A warming pattern continued in March 2012, and the surface temperature anomalies were close to, or exceeded, $5 \mathrm{~K}$ north of the Greenland, Barents and Kara seas (Fig. 5). However, the vertical distribution of temperature and water vapour (averaged over $65-75^{\circ} \mathrm{N}$ ) indicates an absence of significant atmospheric thermodynamic anomalies (Fig. 6). In fact, March 2007 surface temperature anomalies did not extend much beyond the Barents and Kara seas into the central Arctic because advection of colder, drier air from the North American and eastern Siberian regions dominated from near surface through much of the troposphere, resulting in negative anomalies in temperature and WV over Alaska, eastern Siberia and neighbouring sea areas.

During April 2012, the large-scale circulation pattern shifted, resulting in strong vertical cooling and drying over the North Atlantic region. A similar pattern occurred during April 2007. However, the North Atlantic cooling was weaker while the Eurasian and Siberian regions' warming was large and significant throughout much of the troposphere (Fig. 6), directly leading to positive skin temperature anomalies larger than $4 \mathrm{~K}$ (Fig. 5). Surface and mid-tropospheric warming was observed north of the Canadian archipelago and the Beaufort Sea during May 2012, a feature that was clearly opposite to that observed during May 2007 (Fig. 6).
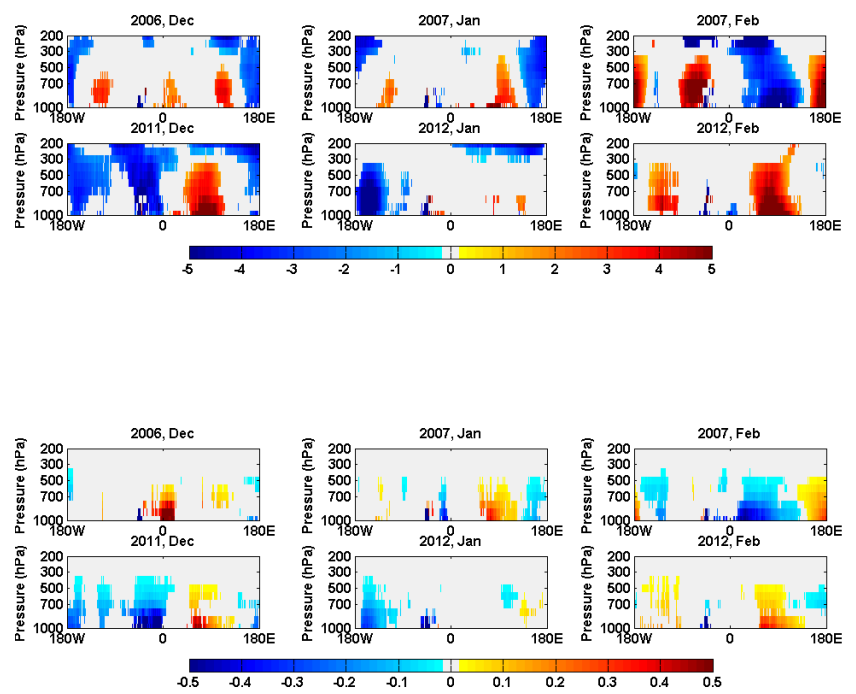

Fig. 4. Meridional-vertical distribution of 2007 and 2012 winter (DJF) temperature anomalies [K] (top two rows) and water vapour mass mixing ratio anomalies $\left[\mathrm{g} \mathrm{kg}^{-1}\right]$ (bottom two rows). Temperatures and water vapour mixing ratios at each pressure level are averaged over the latitude band of $65-75^{\circ} \mathrm{N}$. The anomalies that lie below the one-sigma level are masked out.

Despite differences in skin temperature anomalies between 2007 and 2012, the vertical thermodynamic profile anomalies were more consistent between the two years during spring than for winter. Moist static energy (MSE) is the sum of the dry thermodynamic energy, gravitational potential energy and latent energy of vapourisation, and we estimate the MSE from AIRS profiles of temperature, geopotential height and water vapour. Mass-weighted vertically integrated $\operatorname{MSE}\left[\mathrm{J} \mathrm{m}^{-2}\right]$ is calculated from

$\mathrm{MSE}=\int_{p_{100 \mathrm{hPa}}}^{P_{1000 \mathrm{hPa}}}\left[c_{p} T+g \mathrm{~d} z+L q\right] \frac{\mathrm{d} p}{g}$,

where $c_{p}$ is the specific heat of air $\left[1004 \mathrm{~J} \mathrm{~kg}^{-1} \mathrm{~K}^{-1}\right.$ ], $T$ is temperature $[\mathrm{K}], g$ is the gravitational acceleration $\left[9.81 \mathrm{~m} \mathrm{~s}^{-2}\right], z$ is height $[\mathrm{m}], L$ is the latent heat of vapourisation $\left[2.5 \times 10^{6} \mathrm{~J} \mathrm{~kg}^{-1}\right], q$ is the water vapour mixing ratio $\left[\mathrm{kg} \mathrm{kg}^{-1}\right]$, and $p$ is pressure $[\mathrm{Pa}]$. Figure 7 shows the mean meridional-vertical integral from $65-85^{\circ} \mathrm{N}$ of MSE monthly anomalies calculated from Eq. (1) for December through May; anomalies for all years are shown in grey, while 2007 and 2012 anomalies are in blue and red, respectively. Interestingly, even though the 2007 and 2012 MSE anomalies were not always significantly larger than the respective monthly anomalies for all years 2003-2012, the spatial similarities in MSE anomalies for 2007 and 2012 are striking. During winter, these anomalies generally tend to be lower over the North American sector, becoming more positive over the Eurasian sector (Fig. 7, top panels). Surface and 

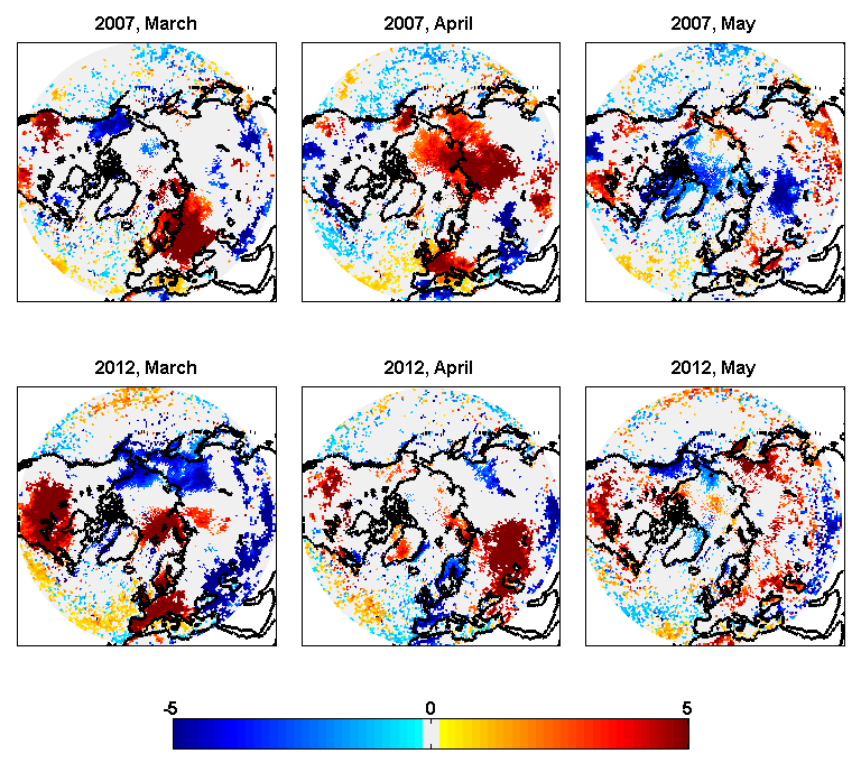

Fig. 5. Surface skin temperature $[K]$ anomalies for the MAM months of 2007 (top row) and 2012 (bottom row).

atmospheric warming during 2012 over the Eurasian sector are consistent with a larger transport of MSE (warmer atmospheric temperatures, deeper geopotential thicknesses and greater moisture) in this region (positive anomalies) compared to small or negative anomalies during 2007. This pattern also persisted into March; however, by April, the MSE anomalies were negative and significant over the North Atlantic and western Eurasia and positive and significant over eastern Siberia and western North America. MSE anomalies between 2007 and 2012 were most different during May, when a strong 2012 negative anomaly persisted and increased from the previous month (Fig. 7).

This warm air preconditioning in winter and early spring was followed by persistent northerly near-surface winds in subsequent months in the Fram Strait, Greenland Sea and Norwegian Sea, with the difference that these winds were stronger in 2012 compared to 2007 and persisted throughout late spring and summer (Fig. 8). In 2007, the southerly and southwesterly winds blowing over the northern northeast Atlantic, to some extent, did not provide favourable conditions for efficient sea ice transport out of the Arctic (via the Atlantic sector), especially in April and May. In contrast, in 2012, northerly winds were not only stronger but also extended toward more southerly latitudes $\left(\sim 55^{\circ} \mathrm{N}\right)$. Therefore, favourable conditions prevailed over the entire Fram Strait and Greenland Sea for increased sea ice transport out of the Arctic in late spring and early summer of 2012. Ogi and Wallace (2012) have previously reported on the importance of near-surface wind in regulating sea ice transport out of the Arctic via the Fram Strait. They investigated wind patterns over the Arctic from May onwards. We show here that, in contrast to 2007 , the near-surface winds were already
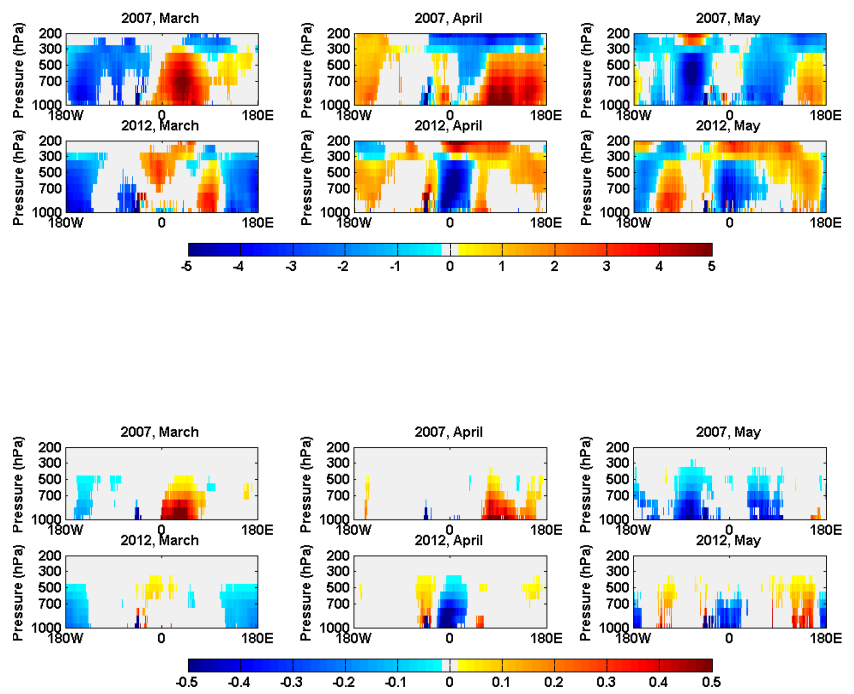

Fig. 6. Same as in Fig. 4, but for the MAM months.

favouring sea ice export in April of 2012 via the Fram Strait (Fig. 8). In addition to the surface wind patterns, advection of cold and dry air from the central Arctic over the Fram Strait and Norwegian and Greenland seas occurred during the late spring and early summer of 2012, clearly evident in the vertical thermodynamic anomalies (Fig. 6) and MSE anomalies (Fig. 7). These anomalies are consistent with negative surface temperature anomalies over these regions (Fig. 5). This lends further support to the case that outward sea ice transport may have been efficient. It is also to be noted that in 2007 these anomalies were in fact mostly positive over the southern Greenland and Norwegian seas. Thus, in 2012 winds played an even more important role compared to the previous 2007 SIM events.

\subsection{Summer evolution}

From May 2012 onward, a noticeable surface warming up to $3 \mathrm{~K}$ was observed over the Canadian Basin (especially along the coast) and Victoria and Banks islands (Fig. 5, lower right panel and Fig. 9). This warming pattern persisted throughout early summer. In sharp contrast to 2007, cooling was observed over the East Siberian Sea in 2012 during summer (Fig. 9). Advection of warm and humid air over the East Siberian Sea region, which was mostly blamed for accelerating sea ice melt in summer 2007, was in fact very weak in summer 2012 (Fig. 10). Instead, warmer and moister air was observed primarily over central and western Siberia during the onset of summer, gradually transitioning to a nearly pan-Arctic cooling and drying over much of the lower and middle atmosphere during August (Fig. 10). Unlike the transitioning (warming to cooling) atmosphere of 2012, the warm and moist anomalies of 2007 remained semi-persistent over the East Siberian, Chukchi and Beaufort seas during summer (Fig. 10). The fact that atmospheric 

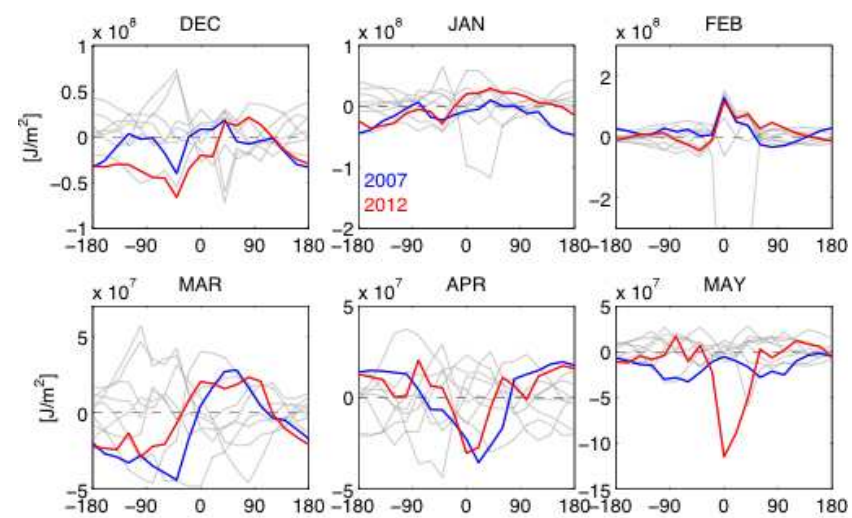

Fig. 7. Meridional means of mass-weighed vertically-integrated MSE $\left[\mathrm{J} \mathrm{m}^{-2}\right]$ monthly anomalies for the latitude band of $65-85^{\circ} \mathrm{N}$. Monthly anomalies are estimated relative to the 2003-2012 monthly averaged vertical integrals of MSE at each AIRS grid point between $65-85^{\circ} \mathrm{N}$. Meridional averages are shown for $20^{\circ}$ bins. Grey lines are all months (DJFMAM) for 2003-2012, with 2007 and 2012 highlighted in blue and red, respectively.

anomalies weakened or became negative during July and August 2012 suggest that sea ice preconditioning from anomalous atmospheric thermodynamics and wind forcing during the winter and spring months were likely more important for the subsequent 2012 record SIM than atmospheric anomalies during the summer. However, it requires mention that peak melting does occur during the summer months when solar radiation is strongest, and thus the total ice melt is a convolution of processes occurring throughout the year. The role of preconditioning itself could either be to enhance or dampen the rate of ice melt, thus setting the stage for eventual maximum melt in September.

Cloud cover plays an important role in seasonal sea ice growth and melt. For example, increased longwave surface forcing due to an increased cloud greenhouse effect in winter may inhibit the build-up of sea ice. However, in summer, increased cloud cover tends to reflect solar radiation that would have reached the surface, thus cooling it and possibly retarding sea ice melt. The transition from positive to negative surface radiative forcing of clouds occurs roughly during the late spring in April-May, and vice versa in August-September, depending on latitude, surface albedo and cloud microphysical characteristics (Walsh and Chapman, 1998; Shupe and Intrieri, 2004; Sedlar et al., 2011; Persson, 2012). While the summer of 2007 was characterised by reduced cloudiness over the Beaufort and Chukchi seas (Pacific sector of the Arctic) and north of Greenland (Fig. 11), in the summer of 2012 cloudiness actually increased over these regions, especially over the East Siberian Sea. Reduced cloudiness was instead observed over the southeastern Canadian Basin and Victoria and Banks islands (Fig. 11). Consistent with these summer cloud cover anomalies, surface warming was observed over the southeastern Canadian Basin and around Victoria

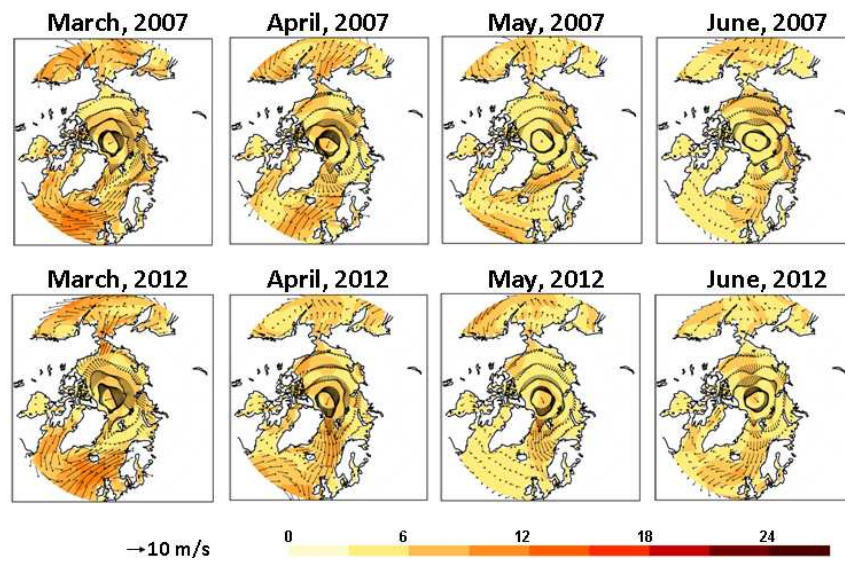

Fig. 8. Near-surface winds $(1000 \mathrm{hPa})$ during spring and early summer based on ECMWF global atmospheric reanalysis-Interim Reanalysis. The data for June 2012 are from the The European Centre for Medium-Range Weather Forecasts (ECMWF) forecasts.

and Banks islands, and cooling over the East Siberian Sea, as mentioned above.

Figure 12 shows the temporal evolution of sea ice concentration from May through August for 2007 and 2012. Included are geographic sea ice melt regions (ellipses) that we identify as being most affected by preconditioning and seasonal transitions of large-scale atmospheric advection of heat and moisture and dynamical wind forcing.

It is interesting to note that the sea ice concentration already in May was less in 2012 compared to 2007 over the Beaufort, East Siberian and Kara seas. This is likely a consequence of an increase in first-year ice that emerged after another large ice melt year during 2011. While the East Siberian Sea (or the Pacific sector in general) experienced advection of heat and moisture and subsequent rapid melting in 2007, there were three hot spots in 2012 that experienced above- or below-normal anomalies in temperature, water vapour and clouds. Significant melting occurred during 2012 in the Kara and Barents seas, already visible in May and June (Fig. 12), causing the marginal ice zone to be pushed further north during 2012. Additionally, enhanced MSE resulting from advection of heat and moisture over the eastern Beaufort Sea led to an ice-free anomaly in this region already in May and June during 2012, which was not observed in 2007 until during July. Therefore, the sea ice melt from these three sides of the marginal sea ice zone was, as a result, more efficient in 2012.

\section{Discussions and conclusions}

As a result of increased greenhouse gas forcing and associated feedbacks, Arctic sea ice has rapidly been melting during the last decade. The sea ice is continually thinning, making the Arctic cryosphere sensitive to small- and shortscale changes in the state of the atmosphere, which can either 

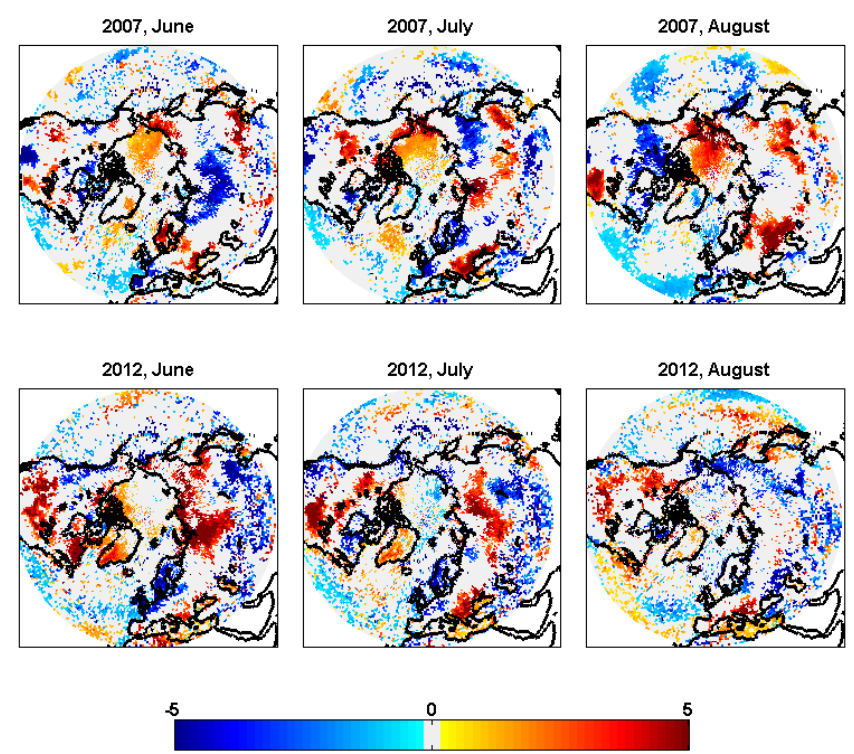

Fig. 9. Surface skin temperature $[\mathrm{K}]$ anomalies for the JJA months of 2007 (top row) and 2012 (bottom row).

retard or accelerate this already declining trend in sea ice extent and thickness. Therefore, it is important to investigate how the atmosphere manifests itself during record minimum events so as to understand commonalities and differences, which can further be exploited to improve prediction skills of such events and to study and model relevant processes.

Here, an overview of the thermodynamic state of the Arctic atmosphere during two recent record minimum sea ice extent events (2007 and 2012) is presented using data from the Atmospheric Infrared Sounder (AIRS) instrument onboard Aqua satellite, which has the capability to provide full-scale 3-D information on thermodynamics. Winter and spring atmospheric preconditioning of sea ice growth and retardation are concluded as a common, important contributor to the subsequent ice extent minima observed during record sea ice loss years.

Based on the analysis presented, we conclude that the preconditioning of the Arctic atmosphere, especially over three geographical hot spots (Fig. 12), may have lead to favourable conditions for sea ice melt and its faster transport out of the Arctic in 2012. First, already thinning sea ice, especially from the last few years, was subjected to warming throughout the winter of 2011-2012 over the Fram Strait, Kara, Barents and Greenland seas. Vertical integrals of moist static energy suggest that during winter, the Eurasian sector of the Arctic, comprising many of the seas just mentioned, experienced positive anomalies associated with increased temperature and water vapour advection during 2012. This may have prevented sufficient ice thickening over these areas during winter. Second, stronger and persistent northerly winds over these regions from April 2012 onward facilitated efficient transport of sea ice out of the Arctic. Together with stronger
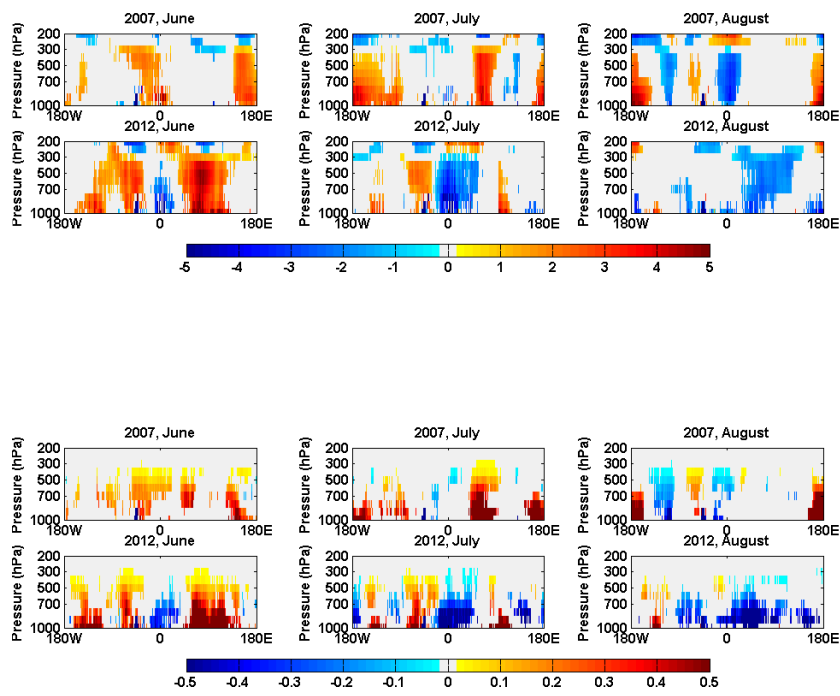

Fig. 10. Same as in Fig. 4, but for the summer months.
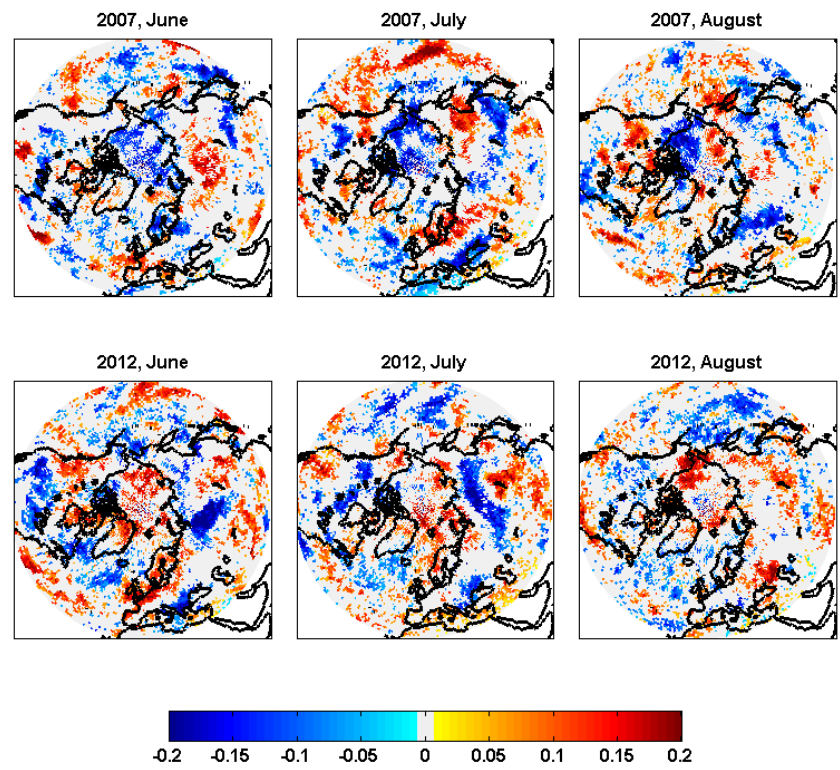

Fig. 11. Cloud fraction anomalies for the JJA months of 2007 (top row) and 2012 (bottom row).

northerly winds, large and significant negative anomalies in moist static energy over the North Atlantic sector during April and May contributed to increased northward advection of heat and moisture further east, enhancing melt in the Kara and Laptev seas during 2012. Third, additional warming over the Canadian Basin and around Victoria and Banks islands from May onward further accelerated sea ice melt from the North American sector. During winter and spring of 2007, northward advection of heat and moisture in the North Atlantic sector was large, but the majority of the central Arctic basin was under the influence of a synoptic circulation pattern that promoted cold air advection 


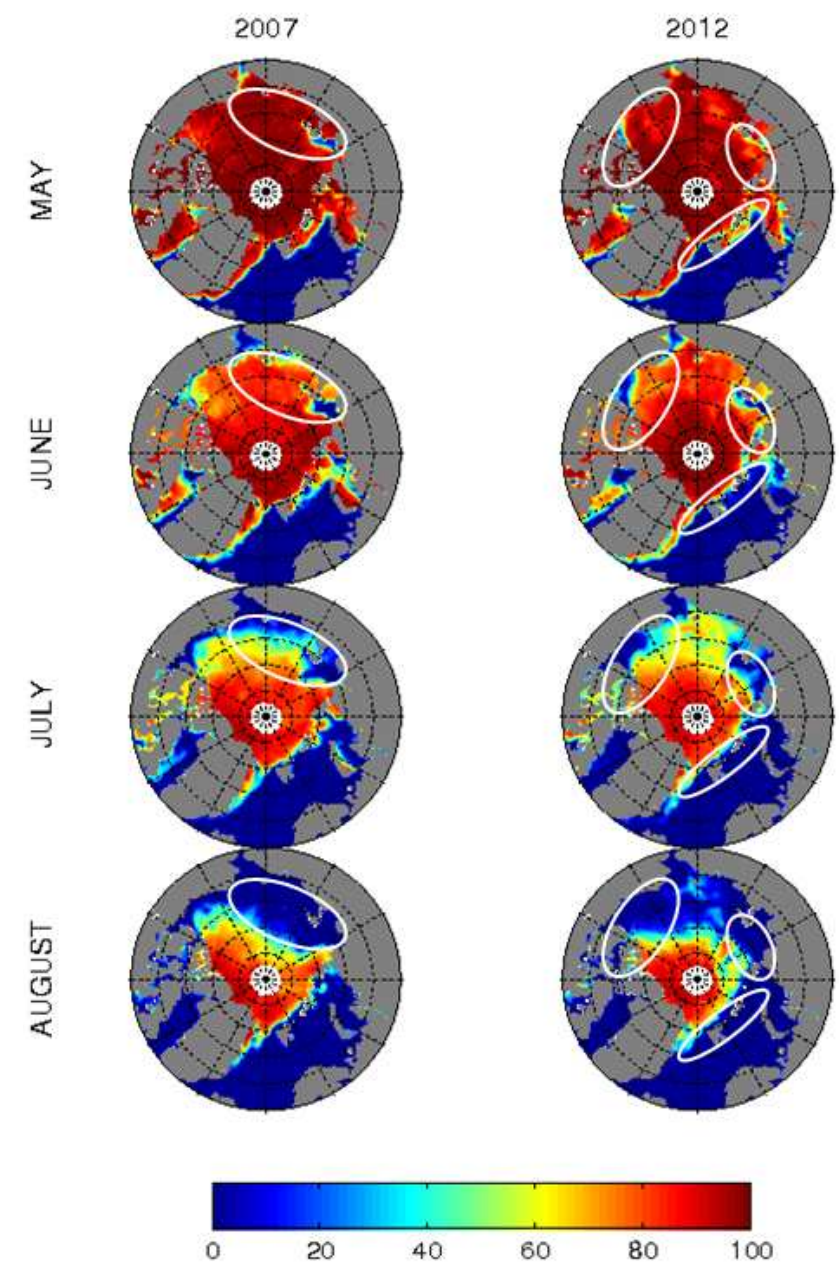

Fig. 12. Monthly mean sea ice concentration from May through August of 2007 (left column) and 2012 (right column). The areas highlighted by white ellipses show regions that experienced accelerated sea ice melt during these years. The same data set as in Fig. 1 is used. The disappearance of sea ice is clearly evident in these highlighted areas.

over much of the Arctic. Not until late spring did the circulation change, allowing a strong preconditioning warming from the Eurasian and Siberian sectors of the Arctic - which appears to have contributed largely to the ice extent mimima in the East Siberian and Laptev seas (Sedlar and Devasthale, 2012; Graversen et al., 2011). The Arctic sea ice was instead warmed from three critical sides (Northern Atlantic, north central Russian and North American sectors) in 2011-2012. These areas played a critical role in 2012, in contrast to the contributions from the Pacific sector in 2007, where warm and humid air advection over the East Siberian and Chukchi seas was mostly blamed for accelerating sea ice melt (Graversen et al., 2011). Although the magnitude and spatial correspondence was not exact, moist static energy anomalies during the SIM years of 2007 and 2012 exhibited the same meridional trends, suggesting a comparable link between at- mospheric thermodynamic preconditioning and subsequent extreme summer sea ice melt. In addition to the three hot spots discussed in this article, a strong cyclone entered the Arctic in August 2012 (Simmons and Rudeva, 2012; Zhang et al., 2013). However, it is worth mentioning that the rate of sea ice melt was already higher since June 2012, long before the occurrence of this particular storm. Zhang et al. (2013) argue that the melting would have been at the record level even without the occurrence of this storm.

All geophysical variables studied here (temperature, water vapour, cloud fraction, geopotential height), wind patterns from ERA-Interim Reanalysis and the spatio-temporal progression of sea ice melt are consistent with the interpretations mentioned above. It is interesting to note that the anomalies observed in geophysical variables are not extreme in the summer of 2012 compared to climatology. However, since the last decade, the sea ice system has been transforming into such a delicate state that even weak but persistent changes in these variables are sufficient to alter the progression of sea ice melt. The role of satellite-based monitoring of atmospheric preconditioning therefore becomes a critical source of information in predicting such future extreme melting events in the Arctic.

Acknowledgements. The authors would like to thank AIRS Science Team and NASA GES DISC for their efforts in making data publicly available for research. We also thank the anonymous referees, whose comments led to substantial improvements in the original manuscript. We further thank Jonas Mortin for packaging sea ice extent data for our purposes and Manu Anna Thomas (SMHI) for helping with wind data. We also acknowledge ECMWF data portal for providing wind fields. This work is supported by the Swedish National Space Board.

Edited by: T. Garrett

\section{References}

Cavalieri, D., Parkinson, C., Gloersen, P., and Zwally, H. J.: Updated yearly, Sea Ice Concentrations from Nimbus-7 SMMR and DMSP SSM/I-SSMIS Passive Microwave Data, Version 1.0. Boulder, Colorado, USA, National Snow and Ice Data Center, 1996.

Chahine, M. T., Pagano, T. S., Aumann, H. H., Atlas, R., Barnet, C., Blaisdell, J., Chen, L., Divakarla, M., Fetzer, E. J., Goldberg, M., Gautier, C., Granger, S., Hannon, S., Irion, F. W., Kakar, R., Kalnay, E., Lambrigtsen, B. H., Lee, S.-Y., Le Marshall, J., McMillan, W. W., McMillin, L., Olsen, E. T., Revercomb, H., Rosenkranz, P., Smith, W. L., Staelin, D., Strow, L. L., Susskind, J., Tobin, D., Wolf, W., and Zhou, L.: AIRS: Improving Weather Forecasting and Providing New Data on Greenhouse Gases, Bull. Am. Meteorol. Soc., 87, 911-926, 2006.

Comiso, J. C.: Large Decadal Decline of the Arctic Multiyear Ice Cover, J. Climate, 25, 1176-1193, doi:10.1175/JCLI-D-1100113.1, 2012. 
Deser, C. and Teng, H., Evolution of Arctic sea ice concentration trends and the role of atmospheric circulation forcing, 1979-2007, Geophys. Res. Lett, 35, L02504, doi:10.1029/2007GL032023, 2008.

Devasthale, A., Willén, U., Karlsson, K.-G., and Jones, C. G.: Quantifying the clear-sky temperature inversion frequency and strength over the Arctic Ocean during summer and winter seasons from AIRS profiles, Atmos. Chem. Phys., 10, 5565-5572, doi:10.5194/acp-10-5565-2010, 2010.

Devasthale, A., Sedlar, J., and Tjernström, M.: Characteristics of water-vapour inversions observed over the Arctic by Atmospheric Infrared Sounder (AIRS) and radiosondes, Atmos. Chem. Phys., 11, 9813-9823, doi:10.5194/acp-11-9813-2011, 2011.

Devasthale, A., Tjernström, M., Caian, M., Thomas, M. A., Kahn, B. H., and Fetzer, E. J.: Influence of the Arctic Oscillation on the vertical distribution of clouds as observed by the ATrain constellation of satellites, Atmos. Chem. Phys., 12, 1053510544, doi:10.5194/acp-12-10535-2012, 2012.

Divakarla, M. G., Barnet, C. D., Goldberg, M. D., McMillin, L. M., Maddy, E., Wolf, W., Zhou, L., and Liu, X.: Validation of Atmospheric Infrared Sounder temperature and water vapour retrievals with matched radiosonde measurements and forecasts, $\mathrm{J}$. Geophys. Res., 111, D09S15, doi:10.1029/2005JD006116, 2006.

Fetzer, E. J.: Preface to special section: Validation of Atmospheric Infrared Sounder Observations, J. Geophys. Res., 111, D09S01, doi:10.1029/2005JD007020, 2006.

Gettelman, A., Walden, V. P., Miloshevich, L. M., Roth, W. L., and Halter, B.: Relative humidity over Antarctica from radiosondes, satellites, and a general circulation model, J. Geophys. Res., 111, D09S13, doi:10.1029/2005JD006636, 2006.

Graversen, R. G., Maurtisen, T., Drijfhout, S., Tjernström, M., and Mårtensson, S.: Warm winds from the Pacific caused extensive Arctic sea-ice melt in summer 2007, Clim. Dyn., 36, 2103-2112, doi:10.1007/s00382-010-0809-z, 2011.

Kahn, B. H., Chahine, M. T., Stephens, G. L., Mace, G. G., Marchand, R. T., Wang, Z., Barnet, C. D., Eldering, A., Holz, R. E., Kuehn, R. E., and Vane, D. G.: Cloud type comparisons of AIRS, CloudSat, and CALIPSO cloud height and amount, Atmos. Chem. Phys., 8, 1231-1248, doi:10.5194/acp-8-1231-2008, 2008.

Kay, J. E. and Gettelman, A.: Cloud influence on and response to seasonal Arctic sea ice loss, J. Geophys. Res., 114, D18204, doi:10.1029/2009JD011773, 2009.

Kay, J. E., L'Ecuyer, T., Gettelman, A., Stephens, G., and O'Dell, C.: The contribution of cloud and radiation anomalies to the 2007 Arctic sea ice extent minimum, Geophys. Res. Lett., 35, L08503, doi:10.1029/2008GL033451, 2008.

Kwok, R., and Rothrock, D. A.: Decline in Arctic sea ice thickness from submarine and ICESat records: 1958-2008, Geophys. Res. Lett., 36, L15501, doi:10.1029/2009GL039035, 2009.

Kwok, R., Cunningham, G. F., Wensnahan, M., Rigor, I., Zwally, H. J., and Yi, D., Thinning and volume loss of the Arctic Ocean sea ice cover: 2003-2008, J. Geophys. Res., 114, C07005, doi:10.1029/2009JC005312, 2009.

L'Heureux, M. L., Kumar, A., Bell, G. D., Halpert, M. S., and Higgins, W. R.: Role of the Pacific-North American (PNA) pattern in the 2007 Arctic sea ice decline, Geophys. Res. Lett., 35, L20701, doi:10.1029/2008GL035205, 2008.
Lindsay, R. W., Zhang, J., Schweiger, A., Steele, M., and Stern, H.: Arctic Sea Ice Retreat in 2007 Follows Thinning Trend, J. Climate, 22, 165-176, doi:10.1175/2008JCLI2521.1, 2009.

Liu, Y., Key, J. R., and Wang, X.: Influence of changes in sea ice concentration and cloud cover on recent Arctic surface temperature trends, Geophys. Res. Lett., 36, L20710, doi:10.1029/2009GL040708, 2009.

Liu, Y., Key, J. R., Liu, Z., Wang, X., and Vavrus, S. J.: A cloudier Arctic expected with diminishing sea ice, Geophys. Res. Lett., 39, L05705, doi:10.1029/2012GL051251, 2012.

Maslanik, J. A., Fowler, C., Stroeve, J., Drobot, S., Zwally, J., Yi, D., and Emery, W.: A younger, thinner Arctic ice cover: Increased potential for rapid, extensive sea-ice loss, Geophys. Res. Lett., 34, L24501, doi:10.1029/2007GL032043, 2007.

Notz, D. and Marotzke, J.: Observations reveal external driver for Arctic sea-ice retreat, Geophys. Res. Lett., 39, L08502, doi:10.1029/2012GL051094, 2012.

Ogi, M. and Wallace, J. M.: Summer minimum Arctic sea ice extent and the associated summer atmospheric circulation, Geophys. Res. Lett., 34, L12705, doi:10.1029/2007GL029897, 2007.

Ogi, M. and Wallace, J. M.: The role of summer surface wind anomalies in the summer Arctic sea ice extent in 2010 and 2011, Geophys. Res. Lett., 39, L09704, doi:10.1029/2012GL051330, 2012.

Overland, J. E. and Wang, M.: Large-scale atmospheric circulation changes associated with the recent loss of Arctic sea ice, Tellus A, 62, 1-9, 2010.

Perovich, D. K., Richter-Menge, J. A., Jones, K. F., and Light, B.: Sunlight, water, and ice: Extreme Arctic sea ice melt during the summer of 2007, Geophys. Res. Lett., 35, L11501, doi:10.1029/2008GL034007, 2008.

Persson, P. O. G.: Onset and end of the summer melt season over sea ice: thermal structure and surface energy perspective from SHEBA, Clim. Dyn., 39, 1349-1371, doi:10.1007/s00382-0111196-9, 2012.

Schweiger, A. J., Zhang, J., Lindsay, R. W., and Steele, M.: Did unusually sunny skies help drive the record sea ice minimum of 2007?, Geophys Res Lett, 35, L10503, doi:10.1029/2008GL033463, 2008.

Sedlar, J. and Devasthale, A.: Clear sky thermodynamic and radiative anomalies over a sea ice sensitive region of the Arctic, J. Geophys. Res., 117, D19111, doi:10.1029/2012JD017754, 2012.

Sedlar, J., Tjernström, M., Mauritsen, T., Shupe, M. D., Brooks, I. M., . Persson, P. O. G, Birch, C. E., Leck, C., Sirevaag, A., and Nicolaus, M.: A transitioning Arctic surface energy budget: The impacts of solar zenith angle, surface albedo and cloud radiative forcing, Clim. Dyn., 37, 1643-1660, doi:10.1007/s00382010-0937-5, 2011.

Skagseth, Ø., Furevik, T., Ingvaldsen, R., Loeng, H., Mork, K. A., Orvik, K. A., and Ozhigin, V.: Volume and heat transports to the Arctic Ocean via the Norwegian and Barents Seas, in: ArcticSubarctic ocean fluxes: defining the role of Nordic Seas in climate, edited by: Dickson, B., Meincke, J., and Rhines, P., Chap. 2, Springer, Berlin, 1-25, 2008.

Simmonds, I. and Rudeva, I.: The great Arctic cyclone of August 2012, Geophys. Res. Lett., 39, L23709, doi:10.1029/2012GL054259, 2012.

Shupe, M. D. and Intrieri, J. M.: Cloud radiative forcing of the Arctic surface: The influence of cloud properties, surface albedo, and 
solar zenith angle. J. Climate, 17, 616-628, 2004.

Stroeve, J., Serreze, M., Drobot, S., Gearheard, S., Holland, M., Maslanik, J., Meier, W., and Scambos, T.: Arctic Sea Ice Extent Plummets in 2007, Eos Trans. AGU, 89, 13, doi:10.1029/2008EO020001, 2008.

Vihma, T., Jaagus, J., Jakobson, E., and Palo, T.: Meteorological conditions in the Arctic Ocean in spring and summer 2007 as recorded on the drifting ice station Tara, Gephys. Res. Lett., 35, L18706, doi:10.1029/2008GL034681, 2008.

Walsh, J. E. and Chapman, W. L.: Arctic cloud-radiationtemperature associations in observational data and atmospheric reanalyses, J. Clim., 11, 3030-3044, 1998.
Woodgate, R. A., Weingartner, T., and Linday, R.: The 2007 Bering Strait oceanic heat flux and anomalous Arctic sea-ice retreat, Geophys. Res. Lett., 37, L01602, doi:10.1029/2009GL041621, 2010.

Zhang, J., Lindsay, R., Steele, M., and Schweiger, A.: What drove the dramatic retreat of arctic sea ice during summer 2007?, Geophys. Res. Lett., 35, L11505, doi:10.1029/2008GL034005, 2008.

Zhang J., Lindsay, R., Schweiger, A., and Steele, M.: The impact of an intense summer cyclone on 2012 Arctic sea ice retreat, Geophys. Res. Lett., 40, 720-726, doi:10.1002/grl.50190, 2013. 